NASA Technical Memorandum 106963

AIAA-95-2601

\title{
Experimental Results of Hooper's \\ Gravity-Electromagnetic \\ Coupling Concept
}

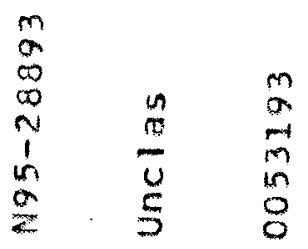

Marc G. Millis and Gary Scott Williamson

Lewis Research Center

Cleveland, Ohio

Prepared for the

31st Joint Propulsion Conference and Exhibit

cosponsored by AIAA, ASME, SAE, and ASEE

San Diego, California, July 10-12, 1995
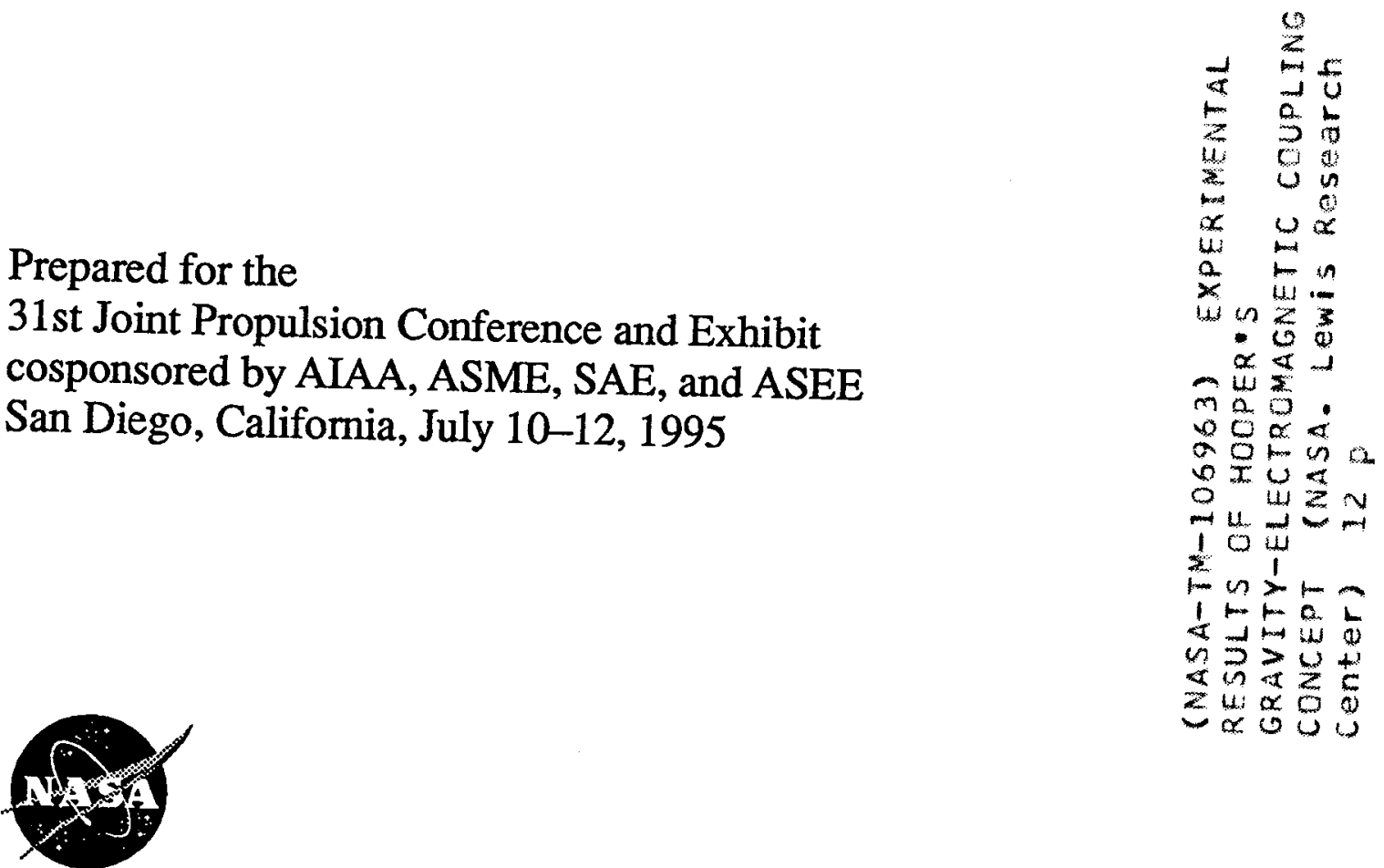

National Aeronautics and

Space Administration 


\title{
AIAA 95-2601 \\ EXPERIMENTAL RESULTS OF HOOPER'S GRAVITY-ELECTROMAGNETIC COUPLING CONCEPT
}

\author{
Marc G. Millis \\ Gary Scott Williamson \\ National Aeronautics and Space Administration \\ Lewis Research Center \\ Cleveland, Ohio
}

\begin{abstract}
Experiments were conducted to test assertions from Patent 3,610,971, by W. J. Hooper that self-canceling electromagnetic coils can reduce the weight of objects placed underneath. No weight changes were observed within the detectability of the instrumentation. More careful examination of the patent and other reports from Hooper led to the conclusion that Hooper may have misinterpreted thermal effects as his "Motional Field" effects. There is a possibility that the claimed effects are below the detection thresholds of the instrumentation used for these tests.
\end{abstract}

\section{INTRODUCTION}

Spaceflight would be revolutionized if it were possible to propel a vehicle by manipulating gravity rather than by using rockets. If a means existed to induce propulsive forces using the coupling between gravity, electromagnetism and spacetime, rocket propellant would no longer be required. By eliminating propellant, spacecraft could become significantly smaller and travel greater distances, unlimited by propellant supply.

Studies by the Air Force and others have examined emerging theories and physical evidence for new approaches toward propulsion breakthroughs $1-5$. These studies identified a variety of unexplored possibilities of varying degrees of complexity and technical maturity. The work of W. J. Hooper is just one of these possibilities 4.

A patent was issued to W. J. Hooper in 1971 for devices which are claimed to produce various anomalous effects 6 . One of the claimed effects is that the weight of a "nonferrous" object would decrease when placed under a self-canceling electromagnetic coil. Formally, the only claims in the patent are about the construction methods for the devices and not the anomalous effects. If this weight reduction effect is genuine, it implies that there is a means to controllably affect gravitational forces using electromagnetics. Although the probability is low that the effect is genuine, such a gravity-electromagnetic coupling would have revolutionary implications for space propulsion.

It is still unknown in science if it is possible to use the coupling between gravity and electromagnetism to manipulate gravity. It is known, however, that gravity and electromagnetism are indeed coupled phenomena. In the formalism of General Relativity this coupling is described in terms of how mass warps the spacetime against which electromagnetic behavior is measured. In simple terms this has the consequence that gravity appears to bend and red-shift light. These observations and the General Relativistic formalism that describes them have been confirmed 7 . Although the effects of gravity on electromagnetics have been confirmed, the possibility of the reverse, of using electromagnetics to affect gravity, is unknown.

The reasons that the Hooper approach was chosen for investigation instead of one of the other possibilities are as follows: The devices are relatively easy and inexpensive to construct and test. Hooper's work is documented well enough to allow duplication. This approach provides empirical evidence which is closer to demonstrating a useful device than are theoretical approaches. There is also no report of Hooper's claims or anything similar being rigorously tested.

Since this research was aimed at detecting a potentially useful effect for space propulsion rather than conducting basic science, only a relatively large effect would be of interest. For this reason, low-cost experiments using standard engineering instrumentation were considered sufficient to determine the viability of the effect. Given that Hooper's claims are based on experiments conducted in the 1960's, it seems reasonable to expect that the effects would be detectable using the improved standard instrumentation available today. It is possible, however, that the simplicity of the experimental equipment used would not detect small effects that would still be of general scientific interest.

This research focused only on testing the empirical claims of Hooper and not on critiquing his theory. To aid in the analysis of the data, however, Hooper's theory 
was examined to determine the expected proportionality of his claimed gravity-electromagnetic coupling effect. A brief description of Hooper's theory is provided next.

\section{THEORY OF W. I. HOOPER}

Hooper conducted experiments with and was awarded patents for a variety of self-canceling electromagnetic coils 6,8. These coils were wound such that equal currents flowed in opposing directions so as to cancel their electromagnetic fields. By eliminating the magnetic fields it was felt that any more subtle effect that would have normally been masked by the magnetic fields could be more easily observed.

Hooper concentrated his efforts on detecting an effect he called the "motional electric field." This field was assumed to cause a slight static charge to build up on the outside of the self-canceling electromagnets.

Most of Hooper's experimental work focused on measuring this slight charge build-up. Hooper thought that this motional electric field might be related to a gravity-electromagnetic coupling, but this connection is not explicitly quantified in his works, nor is it clear what experiments he conducted to explore the gravity connection.

The critical feature claimed of this motional electric field was that it could not be shielded. Hooper felt that if he could generate the motional $\mathrm{E}$ field and show that it was immune to shielding, it would indicate that not all electric fields are electrostatic in nature. This led Hooper to draw similarities between the motional $\mathrm{E}$ field and the gravitational field. He took this one step further and suggested a possible link between electromagnetism and gravity since gravity is the only other field he knew of that was also immune to shielding. Specifically be suggested that the gravitational effects should be directly proportional to his motional electric field effects.

This "motional electric field" was based on ideas suggested by E. G. Cullwick that magnetic flux loops move along with the electrons that cause them 9. This led Hooper to the following equation for his "motional electric field:

$$
\mathbf{E}=\mathbf{B} \times \mathbf{V}_{\mathrm{d}}
$$

Where $\mathbf{E}$ is the "motional electric field", $\mathrm{B}$ is the magnetic induction caused by electrons flowing through the wire, and $\mathbf{V}_{d}$ is the actual velocity ("drift velocity") of the electrons through the wire 6,10. The magnitude of the magnetic induction, $B$, at a distance $r$ radially from the wire is described by the Biot-Savart law for a long straight wire as follows:

$$
B=\frac{\mu_{0} I}{2 \pi r}
$$

Where $\mu_{0}$ is the permeability of free space surrounding the wire and $I$ is the current.

The drift velocity can be written as follows 11 :

$$
\mathrm{V}_{\mathrm{d}}=\frac{i}{\mathrm{~A}}\left(\frac{1}{\mathrm{n} e}\right)
$$

Where $i$ is the current in the wire, $A$ is the cross sectional area of the wire, $\mathbf{n}$ is the number of free electrons in the wire, which for copper is $8.4 \times 10^{28}$ $/ \mathrm{m}^{3}$, and $e$ is the charge of one electron which equals $1.6 \times 10^{-19}$ coulombs.

The drift velocity can also be written as an inverse function of temperature which suggests that the motional electric field can be enhanced by lowering the temperature of the coils. Hooper suggests in the patent that a superconducting self-canceling magnet would make the effect most pronounced since the drift velocity would be substantially higher in superconductors 6 . In the drift velocity equation for normal conductors, however, the temperature dependance appears in the form of the temperature-dependant resistivity. A voltage term also appears in this equation. The combination of resistivity and voltage has the net effect of returning the equation to the form shown above where the drift velocity is only a function of current. The behavior in superconductors relative to the predicted Hooper effect is uncertain.

Both Hooper's motional electric field and the magnetic field are illustrated in figure 1. Note that the polarity of the motional electric field is independent of the direction of the current, whereas the polarity of the magnetic field reverses with reversed current. Using superposition of fields, the magnetic fields cancel but the motional electric fields do not cancel.

To aid in the analysis of the experiments represented by this paper, this motional electric field was used to provide a relative estimate of the anticipated magnitude of any weight change, gravity change, or surface electric field to be observed from conducting the experiments. For a relative comparison of the motional electric field to the variables in the experiment, the following proportionality relationship can be derived:

$$
\mathrm{E} \propto i^{2} \frac{p}{\mathrm{~A}}
$$

Where $\mathrm{E}$ is a relative magnitude of the "motional electric field", $i$ is the current through the wire, $p$ is the 
number of wires per unit width, and $A$ is the cross sectional areas of the wire. Terms for the distance from the coil and for proportionality constants do not appear since these values are constant throughout the tests. The equation as shown is sufficient to calculate a relative comparison of the magnitude of predicted effect. Values calculated from this relationship are listed with the experimental data in Table I.

Although the gravity-electromagnetic effect is the prime interest of this paper, Hooper's own experiments concentrated instead on measuring the charge build-ups. Furthermore, Hooper's most documented experiments did not use the flat coil associated with the weight change claim, but used a self-canceling electromagnet made of a bundle of vertical wires; half of which carry current upward, the other half downward 12. The speculated gravity connection is only mentioned occasionally, such as in reference 6.

Even though it is unlikely that the gravitational effect claimed by Hooper exists, there is no history of this simple test ever being conducted independently. Because of the large benefit if genuine, the simplicity of Hooper's devices, the empirical nature of the claimed effect, and because Hooper's claims are documented well enough to allow designing experiments to verify and characterize its potential, the Hooper claim was selected for experimental investigation.

\section{EXPERIMENTAL CONFIGURATION}

The experiments conducted here duplicate the configuration indicated in the patent, which used a balance beam to search for weight changes of a "nonferrous disk" that was suspended underneath a flat, self-canceling coil 6 . Figure 2 and figure 3 illustrate this configuration (adapted from figures 4 and 6 of reference 6). In addition to searching for the claimed weight change, instrumentation was included to measure the currents and voltages to the coils, to verify that the coils had no net magnetic field, to measure the Earth's gravitational acceleration near the coils, and to measure the surface charge effect as claimed by Hooper. Figure 4 shows the arrangements of the instrumentation around the balance beam. Coils of different gauge wire were constructed to allow testing at different current levels and wire packing densities.

\section{Hooper Coil Construction:}

Four flat magnetic self-canceling coils were built. This flat pancake form most closely duplicates the coil associated with the claimed weight-change effect. Three of the coils were made with insulated wire and the fourth coil was made using a printed circuit board. Table II shows the dimensions, number of turns, wire length, wire gauge, and measured resistance for each of the four coils.

As a base to mount the coils, flat plates of $5 \mathrm{~mm}$ thick polycarbonate sheet were used. A nonferrous and nonmetallic surface was desired to eliminate any magnetic interference or effects. A one inch diameter hole and acrylic plastic hub were placed in the center of the plate to provide an opening for the string that suspended the test mass under the coil. The hub also served as a place to begin wrapping the wire. Carpet tape (adhesive on both sides) was put on the polycarbonate plate to help hold down the wire as the wire was wound.

To provide the counter-current windings, the wire had to be folded back onto itself prior to wrapping. To prepare for this fold, the wire stock was divided evenly on two spools so that its midpoint was between the two spools. The midpoint was folded and wire was drawn from both spools as the coil was wrapped.

To wrap the coils, the folded midpoint was anchored next to the central bub (see figure 3 ) and the wire pair was laid flat on the carpet tape, spiralling out until an outside diameter of about $30 \mathrm{~cm}(\approx 12$ in) was obtained. The two leads were terminated with electrical connectors at this outer edge. To help hold the wire in place, epoxy was applied to the wire during the course of construction. When the coil was completely laid down, another layer of epoxy was applied to ensure that the wire stayed in place. For the 4 AWG wire coil, silicone adhesive was used instead of epoxy, plus plastic wire ties were used to hold the wires together.

The circuit board was printed with the same spiral shape as the wire wound coils. An insulating layer of RTV silicone was painted over its surface. Connectors were placed at the outside edge of the spiral.

\section{Balance Beam Construction:}

The balance beam and "non-ferrous" disk were constructed from acrylic plastic sheet, as were all the support structures for the coils. The structural frame for the balance beam was built from aluminum channel. The whole apparatus was set atop a grounded stainless steel optical bench equipped with vibration isolation mounts.

\section{Instrumentation:}

Power Supplies: Two different power supplies were required to accommodate the range of currents and voltages for the various coils. For the printed circuit coil and the 26 AWG coil, a 0-5 Amp / 0-120 Volt DC 
power supply was used and the currents and voltages were read from both the analog meters on the power supply and from separate digital panel meters. For the 10 AWG and 4 AWG coils, a 0-120 Amp / 0-5 Volt DC power supply was used and the currents and voltages were read from both the analog meters on the power supply and from separate digital panel meters. In all cases the power supplies were set to deliver constant current.

Magnetic Field Meter: To verify that the coils were self-canceling, a magnetic field meter with a magnetometer probe was used. The magnetometer can detect fields as small as 0.0001 Gauss.

Accelerometer: To detect any change in the gravitational field near the coil, a servo accelerometer was placed above the coil with its acceleration axis parallel with the Earth's gravitational field. This alignment tests the hypothesis that a coil might alter the gravitational field of the Earth. The accelerometer, which measures the force on an internal test mass, produces 2.5 Volts/g (where $g$ is the Earth's gravitational acceleration of $9.8 \mathrm{~m} / \mathrm{s}^{2}$ ) and has an advertized resolution of $0.03 \mathrm{mg}$. Its output is read from a voltmeter having a $0.001 \mathrm{mV}$ resolution. This combination results in a detection threshold of $40 \mu \mathrm{g}$.

Balance Beam and Weight Scale: To copy the apparatus as described in the patent and to separate the weight scale from the possible magnetic effects of the coils, a combination of balance beam and weight scale was employed (figure 4). The "non-ferrous" test mass ( $30.5 \mathrm{~cm}$ diam, $6.4 \mathrm{~mm}$ thick, $555 \mathrm{gm}$ acrylic disk) was suspended underneath the test coil by a monofilament line that ran up through the coil's center to one end of the balance beam. A platform was suspended by monofilament lines from the other end of the beam and rested atop the weight scale. Just enough of a preload mass, typically $50 \mathrm{gm}$, was placed on the scale platform to keep a positive load on the scale. The reason that the balance beam was constrained in this manner is because spurious air currents would set the unconstrained beam into oscillations that masked any attempt to determine net shifts in its equilibrium position. An electronic balance with a resolution of $0.001 \mathrm{gm}$ was used. The detection threshold of the whole apparatus was empirically determined to be 0.02 gm.

Surface Voltage: To test for Hooper's associated claim that surface charges build up on the outside of his coils, a two-sided circuit board blank was laid flat on top of the coils to serve as a charge detection capacitor. This board measured $15.3 \mathrm{~cm}$ ( 6 inches) by $30.5 \mathrm{~cm}$ (12 inches) by $0.16 \mathrm{~cm}(1 / 16$ inch) thick and had a measured capacitance of $0.0014 \mu f$. Voltage across the panel was read using a Voltmeter with a $0.001 \mathrm{mV}$ resolution. To minimize noise, a $1 \mathrm{M} \Omega$ resistor was connected across the plates. The input impedance of the voltmeter was $10 \mathrm{M} \Omega$.

In Hooper's reports 12 the charge detection capacitor had its inside face, the side in contact with the coil, grounded. In our tests, two separate detection capacitors were used, one with the inside ground convention of Hooper, and one with the outside grounded.

\section{TEST PROCEDURE}

To test the hypothesis that weight or gravity is affected when current runs through a Hooper coil, simple comparative tests were run between the on state (when current flows through the coils) and the off state (no current flowing). The coils were tested both at room temperature and tested while incased in ice. For both the room temperature and frozen conditions, two current settings were tested with each coil; one with the power supplies set at the highest currents that the coils could handle and the other at half that setting.

On-off comparison measurements were taken separately for the magnetometer, the weight scale, the accelerometer, and the surface voltages. For each parameter, an off measurement was followed immediately by an on measurement, and the difference calculated. This off/on difference was repeated 4 times for each coil and current setting.

Although Hooper typically took his data after letting his devices warm up, the on-off approach was used in our tests for two reasons: First, allowing the apparatus to warm-up would introduce direct and indirect thermal effects, and second, it was assumed that any genuine gravity-electromagnetic coupling would appear immediately in the on state and extinguish immediately in the off state.

The coils were tested in ice to see if there was any direct temperature dependance on the claimed effect. This was largely prompted by Hooper's suggestion that the drift velocities would increase at lower temperatures. Although drift velocity is not a function of temperature at constant current, it was relatively easy to also test the coils while encased in ice.

To encase a coil in ice, the coil was placed in a polycarbonate plastic tub made large enough to hold the coil assembly and it had a central tube to allow passage of the monofilament line that suspended the test mass. Using this ice tub increased the distance between the coil and the suspended test mass by about $5 \mathrm{~mm}$; the thickness of the bottom of the ice tub. The tub was 
filled with distilled water to completely cover the coil and frozen. During tests, occasional visual checks were made to insure that the ice had not melted before the tests were complete.

To explore the option of using superconductors, a cursory estimate was made to determine if it was feasible to use high-temperature superconductors for these tests. It is possible to make square printed circuit boards of high-temperature super conducting film up to about $8 \mathrm{~cm}$ ( 3 inches) a side, and possibly as large as 15 $\mathrm{cm}$ ( 6 inches). The cost to make such a board imprinted with a Hooper coil was estimated to be $\$ 10,000$. This cost and the need to use liquid Nitrogen in the test facility were beyond the scope of this investigation.

\section{EXPERIMENTAL RESULTS}

No weight changes or confirmed alterations of the gravitational field were observed with any of the coils at any of the tested current levels. Freezing the coils made no difference. Results of the on-off toggling tests are summarized in Table I (which includes the detection thresholds of the instrumentation) and are presented in figures 5-11.

Each of the values listed in the last 5 columns of Table I are the averages of the 4 repeated off/on comparison measurements. The \pm levels specified with the data are the larger of either the fluctuation in the meters or twice the standard deviation of the four on-off differences taken for each entry.

Note that the \pm levels are larger than most of the recorded data.

Note too from the magnetic field readings that the coils are not entirely self-canceling. This may have lead to erroneous observations with Hooper's own experiments and did affect the accelerometers in the experiments conducted here.

From figure 5 the effect on the accelerometers from the coils' magnetic fields is evident. From the plot in figure 5, a zero-crossing slope of $-0.8 \mu \mathrm{g} / \mathrm{mG}$ is derived. This slope is used to estimate the amount that each accelerometer reading was compromised by the presence of the magnetic field. The adjusted accelerometer readings, with the magnetic contribution subtracted out, are presented in parentheses with the accelerometer data in Table 1. These adjusted values are used in the subsequent plots of figures $7 \& 11$.

This accelerometer-magnetic field correlation is no surprise given that servo accelerometers use magnetic effects as part of their sensing mechanism. This correlation was further confirmed by subjecting the accelerometer to comparable magnetic fields from a permanent magnet.

The comparisons between the weight change, adjusted gravity change, and surface voltages to the "motional electric field," as predicted by Hooper, are shown in figures 6-9. Relative values for the motional electric field were calculated from equation 4 . These values are listed in Table I. It is clear from the scatter in the data that there are no correlations between the measured parameters and Hooper's motional electric field.

For completeness, the weight changes and adjusted gravity changes are also plotted relative to the power into the coils (volts $\times$ amps). Figures 10 and 11 show that there is no apparent correlation between coil power and the measured weight or gravity changes.

Regarding Hooper's claimed effect of charge buildup on the surface of the coils, the voltage readings of the sensing capacitors were too erratic to reach definite conclusions. Readings were either relatively stable or fluctuated significantly for no discernable reason. Thus, the data for this measurement is highly suspect. As this charge build-up effect is not important to the propulsive implications of Hooper's work, this measurement difficulty was not corrected.

Based on the examination of Hooper's writings, it appears that Hooper routinely allowed his coils to warm-up before taking readings. This warm-up approach invites indirect thermal effects to mask any readings. Hooper went to some lengths in his writings, however, to argue away thermal explanations. It is suspected that any rise of the "nonferrous disk" observed may have been due to upward convection currents in the air that would be induced from the heat generated by the coil. It is uncertain if his surface charge measurements were similarly affected by letting his coils warm up, but this effect is of no concern with respect to propulsion.

\section{CONCLUSIONS}

No weight changes or alterations of the gravitational field of the Earth were observed with any of the coils tested at any current level. No effect was observed even when the coils were encased in ice. Further investigation of Hooper's other writings suggests that Hooper's observations may have been a misinterpretation of thermal effects. Although there is a possibility that the modest detection thresholds of the instrumentation used for these tests would overlook a genuine, but minuscule effect, such an effect would be too small to be of practical value for a propulsion mechanism. Any further research on this possibility is left to interested readers. 


\section{REFERENCES}

1. Mead,F.B.Jr., et al, Advanced Propulsion Concepts - Project Outgrowth, AFRPL-TR-72-31, (JUN 1972).

2. Mead,Jr.F.B., "Exotic Concepts for Future Propulsion and Space Travel", In Advanced Propulsion Concepts, 1989 JPM Specialist Session, (JANNAF), CPIA Publication 528, p.9399, (May 24, 1989).

3. Evans, R.A., (British Aerospace Ltd. Co., Lancashire PR4 1AX), BAe University Round Table on Gravitational Research, Report on Meeting held on March 26-27, 1990, FBS 007, (N91-31729), (DCAF 070093), (Nov 1990).

4. Cravens,D.L., Electric Propulsion Study, AL-TR89-040, Air Force Astronautics Lab (AFSC), (Aug 1990).

5. Forward,R.L., 21st Century Space Propulsion Study, AL-TR-90-030, Air Force Astronautics Lab (AFSC), (Oct 1990). and Forward, 21st Century Space Propulsion Study (Addendum), PL-TR-913022, OLAC Phillips Lab, (June 1991).

6. Hooper,W.J., "All-Electrical Motional Electric Field Generator", US Patent $3,610,971$ (OCT, 1971).

7. Misner,C.W., Thorne,K.S., and Wheeler,J.A., Gravitation, W.H.Freeman \& Co., NY (1973).

8. Hooper,W.J., "Apparatus for Generating Motional Electric Field", US Patent 3,656,013 (APL, 1972).

9. Cullwick, E.G..,Electromagnetism and Relativity, Longsman Green \& Co., p. 245., (1957).

10. Hooper,W J., (Univ of California Berkeley), New Horizons in Electric Magnetic and Gravitational Theory, draft copy, (1969).

11. Halliday, D. and Resnick, R., Physics, Part II, Third edition, John Wiley \& Sons, Inc, NY, p.676678, 686., (1978).

12. Gibson,F.G., The All-Electric Motional Electric Field Generator And Its Potential, Tesla Book
Company, Ventura CA, (1983).

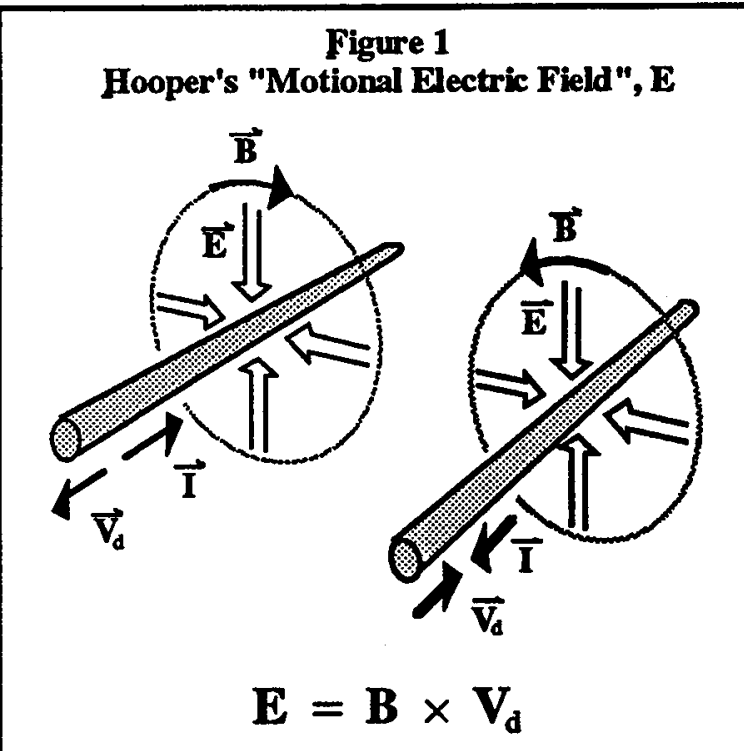

Where $\mathrm{E}$ is the "Motional Electric Field" predicted by Hooper, B is the magnetic induction caused by current in the wire, and $V_{d}$ is the drift velocity of the electrons in the wire. For a collection of such counter-current wires, the equal and opposite magnetic fields cancel.

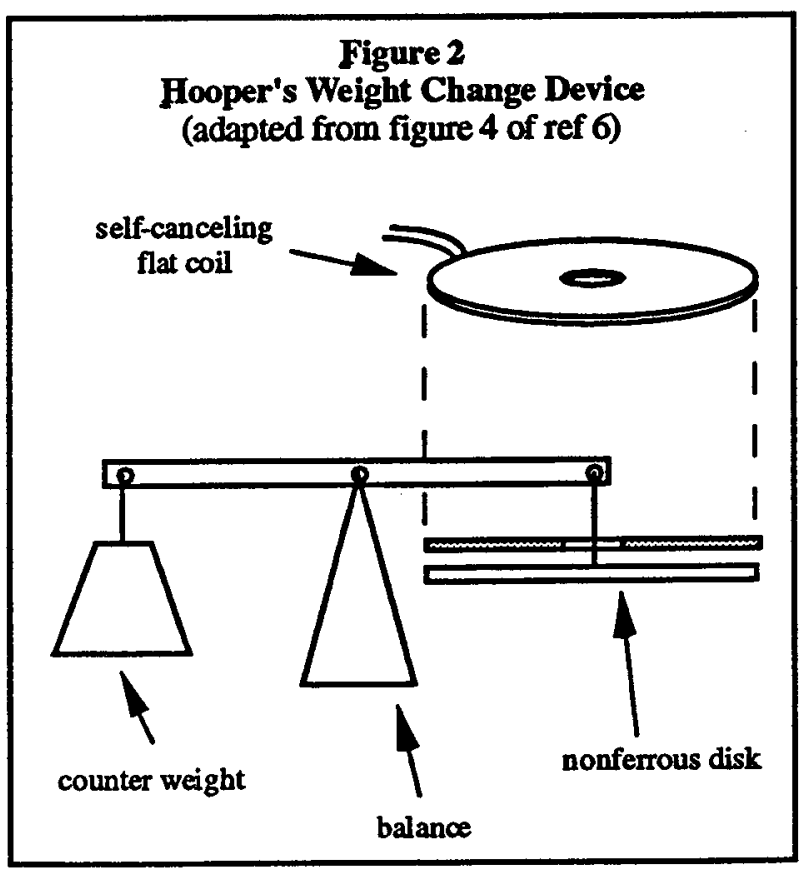



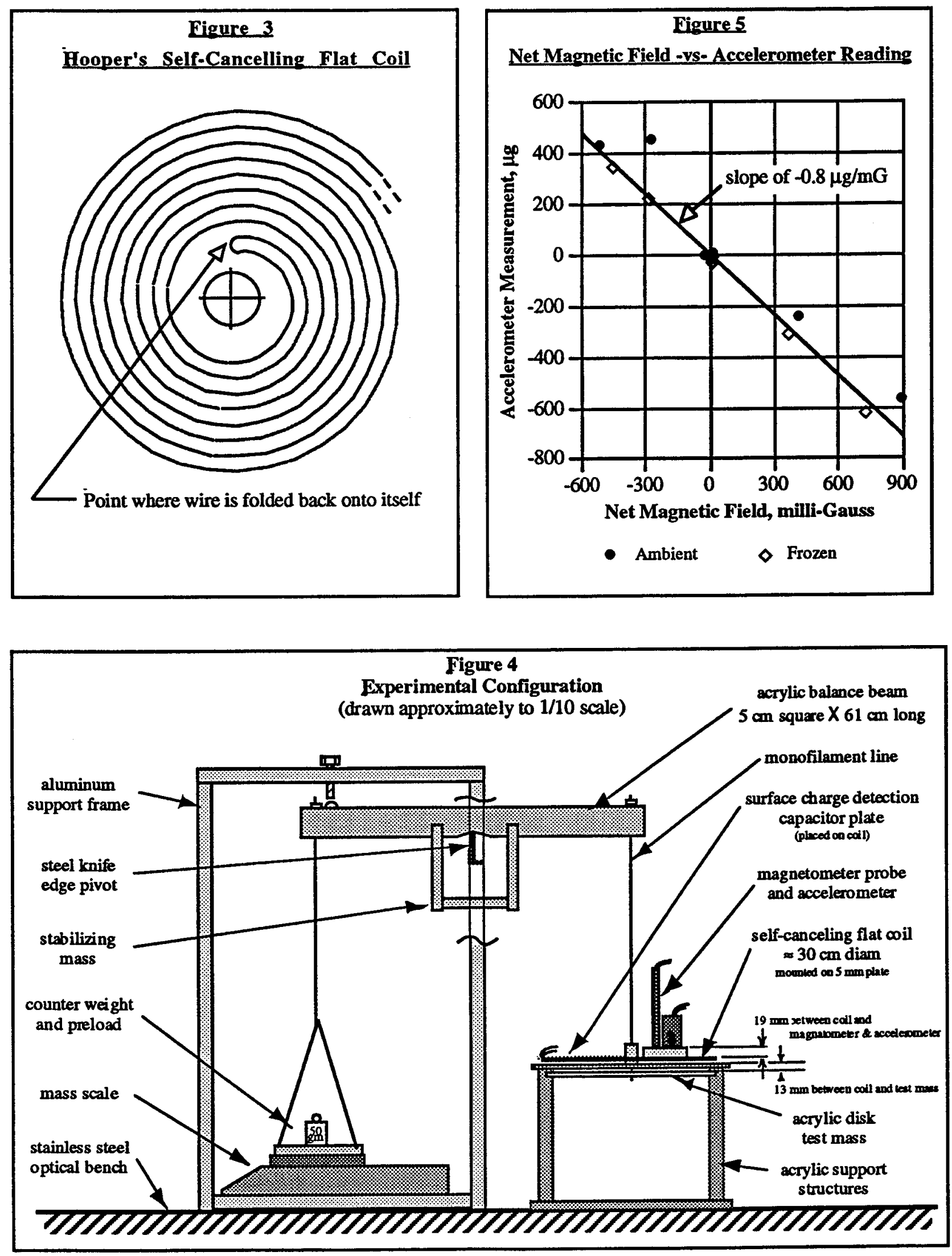

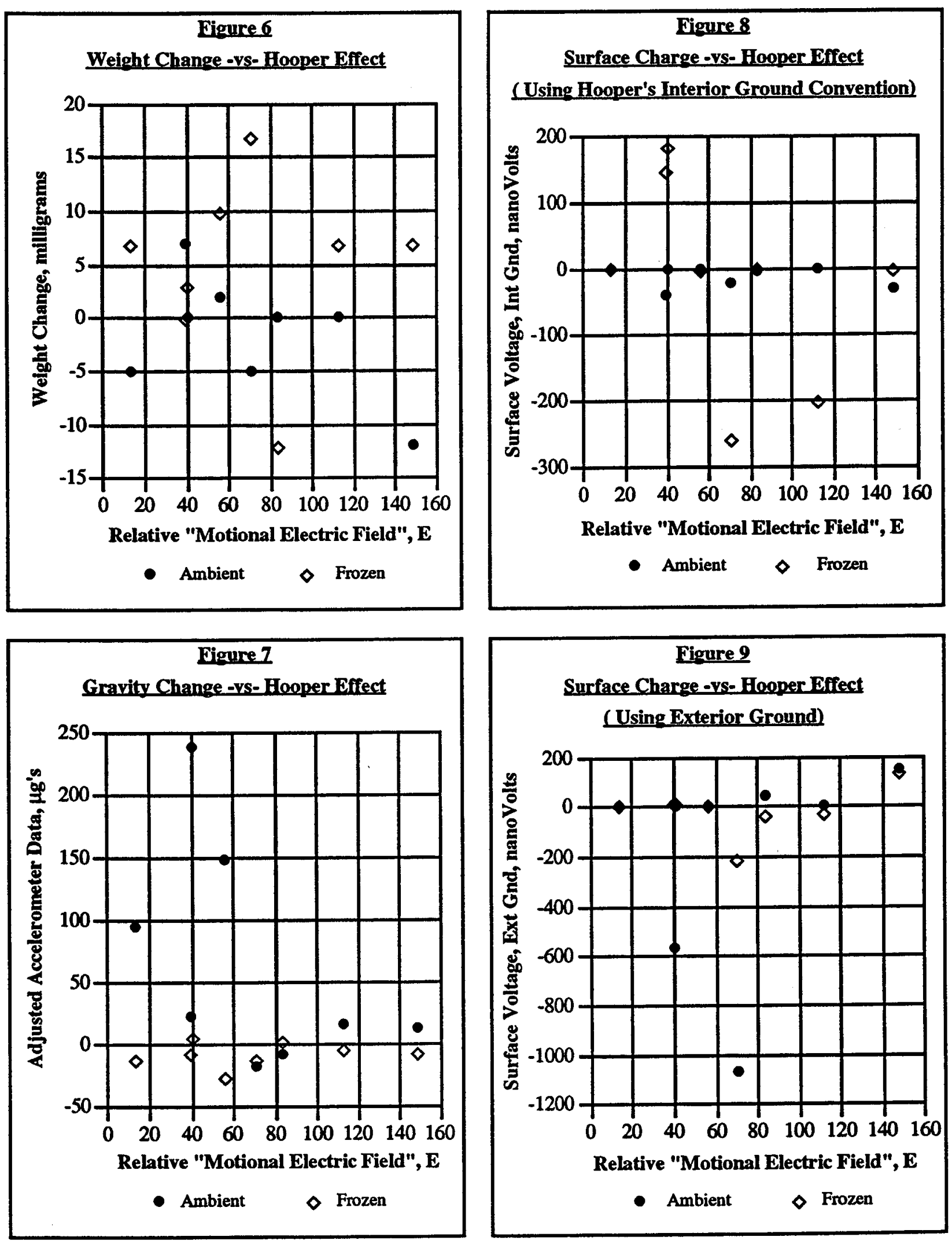

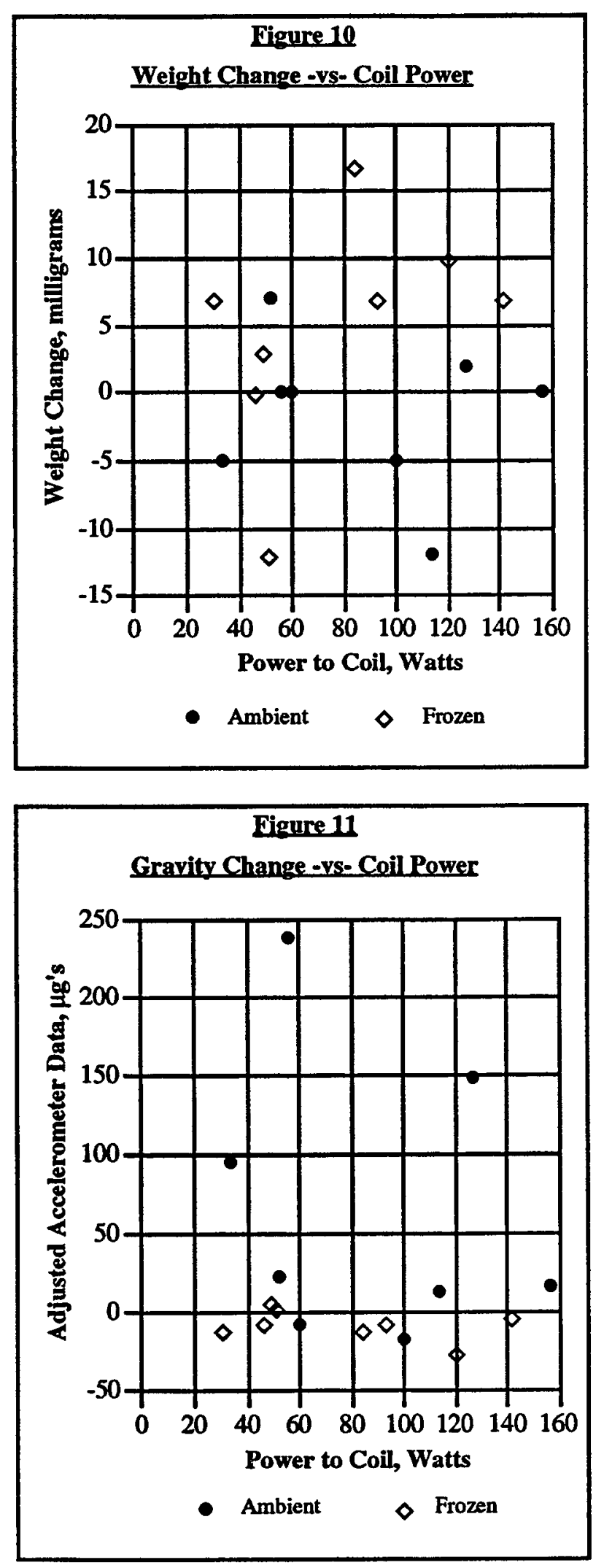
Table I. TEST DATA

\begin{tabular}{|c|c|c|c|c|c|c|c|c|c|}
\hline Coil & \begin{tabular}{|} 
Current \\
into \\
Coil \\
(i) \\
Amps
\end{tabular} & $\begin{array}{c}\text { Voltage } \\
\text { across } \\
\text { Coil } \\
\text { Volt }\end{array}$ & $\begin{array}{c}\begin{array}{c}\text { Calculated } \\
\text { Coil } \\
\text { Resistance }\end{array} \\
\Omega\end{array}$ & $\begin{array}{c}\text { Predicted } \\
\text { Hooper } \\
\text { Effect } \\
\text { E }=i^{2}(p / \mathrm{A})\end{array}$ & $\begin{array}{c}\text { Net } \\
\text { Magnetic } \\
\text { Field } \\
\text { mGauss }\end{array}$ & $\begin{array}{l}\text { Weight } \\
\text { Change } \\
\text { mgram }\end{array}$ & $\begin{array}{c}\text { Gravity Field } \\
\text { Change } \\
\text { meas, (adjusted } \\
\text { by }-0.8 \mu \mathrm{g} / \mathrm{mG} \text { ) } \\
\mu \mathrm{g} \text { 's }\end{array}$ & $\begin{array}{c}\text { Surface } \\
\text { Voltage } \\
\text { Change } \\
\text { (Int Gnd) } \\
\text { nV }\end{array}$ & $\begin{array}{c}\text { Surface } \\
\text { Voltage } \\
\text { Change } \\
\text { (Ext Gnd) } \\
\text { nV }\end{array}$ \\
\hline $\begin{array}{l}\text { Detection } \\
\text { Threshold }\end{array}$ & $-\cdots$ & - & $-{ }_{-\prime}^{\prime}$ & - & $\begin{array}{c}0.1 \\
\text { mGauss }\end{array}$ & $\begin{array}{c}20 \\
\text { mgram }\end{array}$ & $\begin{array}{c}40 \\
\mu g^{\prime} s\end{array}$ & $\begin{array}{c}1 \\
\mathrm{nV}\end{array}$ & $\begin{array}{c}1 \\
\mathrm{nV}\end{array}$ \\
\hline \multicolumn{10}{|c|}{ Ambient Temperature Tests } \\
\hline $\begin{array}{l}\text { Printed } \\
\text { Circuit }\end{array}$ & $\begin{array}{l}1.5 \\
2.0\end{array}$ & $\begin{array}{l}40 \\
57\end{array}$ & $\begin{array}{l}27 \\
29\end{array}$ & $\begin{array}{c}84 \\
149\end{array}$ & $\begin{array}{l}15 \pm 4 \\
17 \pm 10\end{array}$ & $\begin{array}{c}0 \pm 82 \\
-12 \pm 71\end{array}$ & $\begin{array}{c}-20(-8) \pm 80 \\
0(14) \pm 90\end{array}$ & $\begin{array}{l}-4 \pm 14 \\
-29 \pm 36\end{array}$ & $\begin{array}{c}45 \pm 17 \\
149 \pm 64\end{array}$ \\
\hline 26 AWG & $\begin{array}{l}1.5 \\
2.0\end{array}$ & $\begin{array}{l}35 \\
50\end{array}$ & $\begin{array}{l}23 \\
25\end{array}$ & $\begin{array}{l}40 \\
71\end{array}$ & $\begin{array}{l}20 \pm 10 \\
-21 \pm 19\end{array}$ & $\begin{array}{r}7 \pm 67 \\
-5 \pm 33\end{array}$ & $\begin{array}{l}7(23) \pm 230 \\
0(-17) \pm 40\end{array}$ & $\begin{array}{l}-38 \pm 100 \\
-21 \pm 20\end{array}$ & $\begin{array}{c}-567 \pm 2650 \\
-1067 \pm 2550\end{array}$ \\
\hline 10 AWG & $\begin{array}{l}30 \\
50\end{array}$ & $\begin{array}{l}1.9 \\
3.1\end{array}$ & $\begin{array}{l}0.06 \\
0.06\end{array}$ & $\begin{array}{c}41 \\
113\end{array}$ & $\begin{array}{l}-268 \pm 10 \\
-513 \pm 10\end{array}$ & $\begin{array}{l}0 \pm 36 \\
0 \pm 50\end{array}$ & $\begin{array}{c}453(239) \pm 440 \\
427(17) \pm 490\end{array}$ & $\begin{array}{l}0 \pm 4 \\
0 \pm 8\end{array}$ & $\begin{array}{l}4 \pm 9 \\
2 \pm 8\end{array}$ \\
\hline 4 AWG & $\begin{array}{c}50 \\
100\end{array}$ & $\begin{array}{l}0.67 \\
1.28\end{array}$ & $\begin{array}{l}0.013 \\
0.013\end{array}$ & $\begin{array}{l}14 \\
57\end{array}$ & $\begin{array}{c}420 \pm 6 \\
895 \pm 10\end{array}$ & $\begin{array}{c}-5 \pm 50 \\
2 \pm 20\end{array}$ & $\begin{array}{c}-240(96) \pm 80 \\
-567(149) \pm 50\end{array}$ & $\begin{array}{l}-1 \pm 5 \\
1 \pm 4\end{array}$ & $\begin{array}{l}1 \pm 5 \\
0 \pm 4\end{array}$ \\
\hline \multicolumn{10}{|c|}{ Frozen Coil Tests } \\
\hline $\begin{array}{l}\text { Printed } \\
\text { Circuit }\end{array}$ & $\begin{array}{l}1.5 \\
2.0\end{array}$ & $\begin{array}{l}35 \\
47\end{array}$ & $\begin{array}{l}23 \\
24\end{array}$ & $\begin{array}{c}84 \\
149\end{array}$ & $\begin{array}{l}13 \pm 10 \\
18 \pm 15\end{array}$ & $\begin{array}{c}-12 \pm 50 \\
7 \pm 52\end{array}$ & $\begin{array}{c}-7(3) \pm 40 \\
-20(-6) \pm 50\end{array}$ & $\begin{array}{c}2 \pm 5 \\
-1 \pm 17\end{array}$ & $\begin{array}{c}-25 \pm 45 \\
138 \pm 364\end{array}$ \\
\hline 26 AWG & $\begin{array}{l}1.5 \\
2.0\end{array}$ & $\begin{array}{l}31 \\
42\end{array}$ & $\begin{array}{l}21 \\
21\end{array}$ & $\begin{array}{l}40 \\
71\end{array}$ & $\begin{array}{l}17 \pm 10 \\
20 \pm 10\end{array}$ & $\begin{array}{l}0 \pm 100 \\
17 \pm 50\end{array}$ & $\begin{array}{l}-20(-6) \pm 50 \\
-27(-11) \pm 50\end{array}$ & $\begin{array}{c}148 \pm 532 \\
-257 \pm 598\end{array}$ & $\begin{array}{c}19 \pm 37 \\
-205 \pm 132\end{array}$ \\
\hline 10 AWG & $\begin{array}{l}30 \\
50\end{array}$ & $\begin{array}{l}1.7 \\
2.8\end{array}$ & $\begin{array}{l}0.06 \\
0.06\end{array}$ & $\begin{array}{c}41 \\
113\end{array}$ & $\begin{array}{l}-275 \pm 11 \\
-445 \pm 17\end{array}$ & $\begin{array}{c}3 \pm 103 \\
7 \pm 50\end{array}$ & $\begin{array}{r}227(7) \pm 80 \\
353(-3) \pm 40\end{array}$ & $\begin{array}{r}183 \pm 1840 \\
-200 \pm 5340\end{array}$ & $\begin{array}{c}17 \pm 763 \\
-17 \pm 427\end{array}$ \\
\hline 4 AWG & $\begin{array}{c}50 \\
100\end{array}$ & $\begin{array}{l}0.61 \\
1.21\end{array}$ & $\begin{array}{l}0.012 \\
0.012\end{array}$ & $\begin{array}{l}14 \\
57\end{array}$ & $\begin{array}{l}370 \pm 10 \\
735 \pm 10\end{array}$ & $\begin{array}{c}7 \pm 27 \\
10 \pm 30\end{array}$ & $\begin{array}{l}-307(-11) \pm 50 \\
-613(-25) \pm 40\end{array}$ & $\begin{array}{c}3 \pm 10 \\
1 \pm 9\end{array}$ & $\begin{array}{l}10 \pm 13 \\
13 \pm 16\end{array}$ \\
\hline
\end{tabular}

Table II, TEST COIL CHARACTERISTICS

\begin{tabular}{||l|l|l|l|l|l|l||}
\hline \hline $\begin{array}{l}\text { Coil Type } \\
\text { (by wire gauge) }\end{array}$ & $\begin{array}{l}\text { Number } \\
\text { of turn } \\
\text { pairs }\end{array}$ & $\begin{array}{l}\text { Wire Spacing } \\
\text { Density } \\
(p)\end{array}$ & $\begin{array}{l}\text { Wire Cross } \\
\text { Sectional } \\
\text { Area, (A) }\end{array}$ & $\begin{array}{l}\text { Inside Radius } \\
\text { of Coil }\end{array}$ & $\begin{array}{l}\text { Outside Radius } \\
\text { of Coil }\end{array}$ & $\begin{array}{l}\text { Measured } \\
\text { Resistance }\end{array}$ \\
\hline Printed Circuit & 33 & 5.7 wires/cm & $\begin{array}{l}0.015 \mathrm{~mm}^{2} \\
(0.45 \cdot 0.034)\end{array}$ & $1.3 \mathrm{~cm}$ & $12.9 \mathrm{~cm}$ & $26.7 \Omega$ \\
\hline $\begin{array}{l}26 \text { AWG } \\
\text { magnet wire }\end{array}$ & 166 & 23 wires/cm & $0.13 \mathrm{~mm}^{2}$ & $1.0 \mathrm{~cm}$ & $15.3 \mathrm{~cm}$ & $23.7 \Omega$ \\
\hline $\begin{array}{l}10 \text { AWG stranded } \\
19 \text { strands }\end{array}$ & 15 & 2.4 wires/cm & $5.3 \mathrm{~mm}^{2}$ & $1.0 \mathrm{~cm}$ & $13.5 \mathrm{~cm}$ & $0.06 \Omega$ \\
\hline $\begin{array}{l}\text { 4 AWG stranded } \\
19 \text { strands }\end{array}$ & 8 & 1.2 wires $/ \mathrm{cm}$ & $21.2 \mathrm{~mm}^{2}$ & $1.0 \mathrm{~cm}$ & $15.5 \mathrm{~cm}$ & $0.014 \Omega$ \\
\hline
\end{tabular}


Public reporting burden for this collection of information is estimated to average 1 hour per response, including the time for reviewing instructions, searching existing data sources, gathering and maintaining the data needed, and completing and reviewing the collection of information. Send comments regarding this burden estimate or any other aspect of this collection of information, including suggestions for reducing this burden, to Washington Headquarters Services, Directorate for iniormation Operations and Reports, 1215 Jefferson Davis Highway. Sulte 1204, Arlington. VA 22202-4302, and to the Otlice of Management and Budget, Papenwork Reduction Project (0704-0188), Washington, DC 20503.
1. AGENCY USE ONLY (Leave blank)
2. AEPORT DATE
June 1995
3. REPORT TYPE AND DATES COVERED
Technical Memorandum

4. TITLE AND SUBTTILE

Experimental Results of Hooper's Gravity-Electromagnetic Coupling Concept

5. FUNDING NUMBERS

6. AUTHOR(S)

Marc G. Millis and Gary Scott Williamson

WU-307-51-00

7. PERFORMING ORGANIZATION NAME(S) AND ADDRESS(ES)

8. PERFORMING ORGANIZATION

REPORT NUMBER

National Aeronautics and Space Administration

Lewis Research Center

Cleveland, Ohio 44135-3191

E-9719

9. SPONSORING/MONITORING AGENCY NAME(S) AND ADDRESS(ES)

National Aeronautics and Space Administration

Washington, D.C. 20546-0001

10. SPONSORINGMONITORING

AGENCY REPORT NUMBER

NASA TM-106963

AIAA-95-2601

\section{SUPPLEMENTARY NOTES}

Prepared for the 31st Joint Propulsion Conference and Exhibit cosponsored by AIAA, ASME, SAE, and ASEE, San

Diego, California, July 10-12, 1995. Responsible person, Marc G. Millis, organization code 5320, (216) 977-7535.

12a. DISTRIBUTIONAVAILABILTY STATEMENT

12b. DISTRIBUTION CODE

Unclassified-Unlimited

Subject Category 70

This publication is available from the NASA Center for Aerospace Information, (301) 621-0390.

13. ABSTRACT (Maximum 200 words)

Experiments were conducted to test assertions from Patent 3,610,971, by WJ. Hooper that self-canceling electromagnetic coils can reduce the weight of objects placed underneath. No weight changes were observed within the detectability of the instrumentation. More careful examination of the patent and other reports from Hooper led to the conclusion that Hooper may have misinterpreted thermal effects as his "Motional Field" effects. There is a possibility that the claimed effects are below the detection thresholds of the instrumentation used for these tests.

14. SUBJECT TERMS

Antigravity; Gravitation; Electromagnetic coupling; Electromagnetism; Magnetic fields;

Microgravity; Spacecraft propulsion

15. NUMBER OF PAGES

13

16. PRICE CODE

13

\begin{tabular}{c|c|c}
\hline $\begin{array}{c}\text { 17. SECURTY CLASSIFICATION } \\
\text { OF REPORT } \\
\text { Unclassified }\end{array}$ & $\begin{array}{c}\text { 18. SECURITY CLASSIFICATION } \\
\text { OF THIS PAGE } \\
\text { Unclassified }\end{array}$ & $\begin{array}{c}\text { 19. SECURITY CLASSIFICATION } \\
\text { OF ABSTRACT } \\
\text { Unclassified }\end{array}$ \\
\hline
\end{tabular}

NSN 7540-01-280-5500 
